\title{
Innovación tecnológica y externalización de procesos de conocimiento
}

\author{
Benxamín Porto \\ Universidad de Vigo \\ porto@uvigo.es
}

Resumen: La sinergia entre innovación tecnológica y globalización de las TIC facilita la subcontratación global de la interpretación. La digitalización de imágenes y las comunicaciones globales reconfiguran los procesos de imagen médica. La digitalización de imágenes permite la exportación vía Internet a consultores externos globales flexibilizando los procesos de conocimiento y generando incertidumbre en los actores tradicionales. La tecnología como imperativo de la racionalidad y eficiencia transforma los procesos y crea redes horizontales de organizaciones globales que flexibilizan el modelo organizativo tradicional.

Palabras clave: radiólogo, racionalidad, externalización, telerradiología, diagnóstico de imagen.

\begin{abstract}
The synergy between technological innovation and globalization of the ICT facilitates the global outsourcing of interpretation. The digitization of images and global communications rewire medical imaging processes. Images digitalization allows the export via the Internet to global consultants making them flexible knowledge processes and creating uncertainty in the traditional actors. The imperative of rationality and efficiency technology transforms processes, and create horizontal networks of global organizations that make flexible the traditional organisational model
\end{abstract}

Keywords: radiologist, rationality, outsourcing, teleradiology, image diagnosis 


\section{Introducción}

La sanidad es un sector atravesado por un fuerte vector tecnológico. El desarrollo de muchas de las especialidades médicas está vinculado a las tecnologías, como es el caso de la radiología, la nefrología, el análisis en laboratorios, etc. El objetivo de este trabajo es explorar las relaciones entre las tecnologías del diagnóstico de imagen y las tecnologías de la información y la comunicación (TIC) y sus consecuencias organizativas, como la externalización de los procesos de interpretación radiológica.

El objetivo de los médicos clínicos es el diagnóstico o etiquetado clínico de la enfermedad para establecer el plan terapéutico. Para ello utilizan técnicas, como la entrevista, la observación o la exploración física, con el fin de recabar información y establecer el juicio clínico del enfermo. Cada juicio clínico constituye una hipótesis a contrastar. $\mathrm{Su}$ contraste se puede efectuar mediante diferentes pruebas, unas practicadas con el arsenal del propio médico y otras llevadas a cabo por actores que controlan ciertas tecnologías. Antes el arsenal tecnológico de los médicos clínicos era muy limitado (estetoscopio, termómetro, esfigmomanómetro, martillo y poco más), pero progresivamente se fue incrementando con recursos tecnológicos cada vez más sofisticados. Así surgieron los laboratorios de análisis de sangre y tejidos, las imágenes corporales mediante diferentes técnicas, la electrocardiografía, etc. La Organización Mundial de la Salud (OMS) considera tecnologías sanitarias los medicamentos, los equipos y dispositivos tecnológicos, los procedimientos médicos y quirúrgicos, los modelos organizativos y los sistemas de apoyo ${ }^{1}$. En este trabajo el término tecnología lo vamos a utilizar para referirnos a los equipos técnicos.

La industria de la tecnología sanitaria pone a disposición de los profesionales y los consumidores una serie de innovaciones farmacológicas y de equipamientos. La mayoría de éstas se centran en los hospitales, que pasan a ser organizaciones tecnológicamente complejas para el diagnóstico y tratamiento de la enfermedad. La innovación es la aplicación de nuevos conceptos o ideas, productos, servicios y prácticas para incrementar la productividad (González López-Valcárcel, 2005). Los elementos determinantes de las innovaciones tecnológicas dentro de las organizaciones sanitarias son muy variados (Fleuren, Wiefferink y Paulussen, 2004). Muchas innovaciones sanitarias tienen un origen exógeno en la industria tecnológica, las políticas nacionales de $\mathrm{I}+\mathrm{D}$, etc., pero otras innovaciones derivan de factores endógenos, como la rivalidad entre especialistas por apropiarse de tecnologías y ampliar así su poder profesional. Actualmente, la tecnología sanitaria representa el $8 \%$ del gasto sanitario total y se estima que un tercio del incremento anual de costes se debe a la incorporación de avances tecnológicos en la práctica clínica. Actualmente, la mayoría de países desarrollados se

1 OMS. Tecnologías sanitarias esenciales. Disponible en: http://apps.who.int/gb/ebwha/pdf_files/EB118/B118_15sp.pdf [Consulta el 15/2/2010] 
enfrentan al reto del rápido aumento de los costes sanitarios, que contrasta con la escasez de recursos económicos.

\section{Racionalidad y tecnología}

Para Max Weber, la racionalidad es lo que caracteriza a las sociedades avanzadas occidentales. Racionalidad y eficiencia son el eje de la relación entre objetivos y medios. La burocracia es una herramienta técnica del proceso racional científico. La racionalidad y la burocracia son consustanciales al proceso de «modernización» social (Weber, 2003). Las tecnologías son un medio burocrático de la racionalidad instrumental construido por los humanos para alcanzar objetivos. En su libro Ciencia y técnica como ideología, Habermas (1984) plantea que la técnica es la objetivación de la acción racional con respecto a los fines. La evolución de la técnica responde a la estructura de la acción racional del trabajo humano, al que sustituye de manera ventajosa, por lo que es imposible renunciar a la tecnología. Para Habermas, la racionalidad de la tecnología sería el instrumento burocrático de la nueva servidumbre que domina al hombre.

Las implantaciones tecnológicas no son decisiones neutrales, porque producen impactos en los sistemas organizativos y sociales que benefician a unos grupos y generan costes a otros. Munford Lewis (2000) menciona cómo la innovación tecnológica del reloj transformó la forma de vida de la humanidad. Para Habermas, la tecnología es impuesta por la ideología dominante con la finalidad de dominar. Las sociedades occidentales industriales desarrollan amplios procesos de racionalización que subordinan ámbitos y actores sociales a los criterios de la decisión racional técnica. Generalmente, las decisiones sobre la implantación tecnológica responden a los criterios de racionalidad económica e instrumental de los actores que gestionan los sistemas, pero también a la fascinación y el prestigio tecnológicos que reportan a sus controladores. Peiró y Bernal-Delgado (2006) sugieren que la «fascinación tecnológica» explica que el Sistema Nacional de Salud español (SNS) se centre más en la tecnología que en las necesidades de sus pacientes.

La burocracia de Weber sirve de modelo a Mintzberg (1984) para establecer una relación entre la implantación tecnológica, la formalización de procesos, el grado de control y la centralización de la autoridad. La formalización de los procesos de trabajo permite integrarlos en dispositivos tecnológico-burocráticos. Una vez introducidos los procesos en la tecnología, el control de la autoridad es invisible porque está insertado en la máquina. El objetivo de toda burocracia, incluida la profesional, es formalizar los procesos para la especialización profesional. 


\section{Ciencia, tecnología y sociedad}

Los estudios de la sociología de las tecnologías se pueden agrupar en tres perspectivas: el constructivismo social de la ciencia y la tecnología (SCOT), la teoría del actor-red y la historia de los sistemas sociotécnicos.

Para los autores de la escuela constructivista de la tecnología, como Pinch y Bijker (1987), el cambio tecnológico es contingente, heterogéneo y emergente, al igual que el social y el económico. Las tecnologías nacen del conflicto, la diferencia o la resistencia entre promotores y afectados por ellas. Los estudios de casos analizados por esta escuela muestran que las estrategias diseñadas por distintos actores sociales están orientadas al control de la tecnología para mejorar la posición de los promotores respecto de los adversarios.

Para la teoría del actor-red, el concepto de actor engloba a actores humanos y no humanos, tales como herramientas, máquinas, diseños, instituciones, etc. Esta teoría rechaza la dicotomía entre actores sociales y objetos materiales, entre humanos y no humanos, y plantea que hay que hablar de redes de estrechas relaciones entre todos estos actores. Para autores de esta corriente, como Latour (1992) y Callon (1995), los procesos de innovación tecnológica son el resultado de una lucha entre actores que intentan imponer su definición del problema que la tecnología trata de resolver.

Los estudios de los sistemas sociotécnicos aplican la teoría de sistemas a la historia de la tecnología para desvelar las mutuas interacciones entre tecnología y sociedad, más allá de las discusiones sobre supuestos determinismos de uno u otro tipo. Las tecnologías son analizadas como sistemas constituidos con componentes heterogéneos. Para Hughes (1996), las interacciones entre tecnología y sociedad fomentan nuevas tecnologías que modifican las relaciones sociales, pero también surgen nuevos factores sociales que permiten a ciertos actores reconfigurar las tecnologías ya existentes para proteger sus intereses.

Las aportaciones anteriores son criticadas desde la «escuela» de críticos culturales americana, porque se desentiende de las consecuencias sociales de la elección técnica. Para esta corriente, es necesario evaluar y controlar el desarrollo tecnocientífico y desvelar los intereses y procesos sociales que están detrás de las elecciones tecnológicas. Para Winner (1987), referente antitecnológico y del movimiento «neoludita», la tecnología modifica de manera sutil e inadvertida nuestra autoimagen y nuestro papel individual en la sociedad. La tecnología se autonomiza del ser humano y remodela negativamente las condiciones de vida de amplias capas de la población (Winner, 1994). Las aparentes elecciones instrumentales (de técnicas) se convierten en opciones que terminan condicionando las formas de vida social y política de las personas. Por ello plantea que aceptar acríticamente una tecnología sin evaluar políticamente su impacto humano supone asumir un contrato social implícito cuyas condiciones y consecuen- 
cias sólo advertimos con el paso del tiempo. Considera las tecnologías inherentemente políticas, porque la decisión de adoptar una u otra o modificar las ya existentes genera efectos deseados e indeseados. Postman (1994) considera casi imposible eliminar o reducir los cambios tecnológicos porque son muchos los intereses económicos en juego. Para este autor, todo cambio tecnológico no es aditivo sino ecológico al transformar el medio en que se implanta, y a partir de ahí ya nada vuelve a ser igual.

Todo este debate se articula alrededor del determinismo: ¿tecnológico o social? Para el determinismo social, son las necesidades de la sociedad las que promueven el nacimiento o la implantación de las tecnologías. En cambio, los deterministas tecnológicos consideran que la relación entre tecnología y sociedad es unidireccional y condicionante de la estructura y el cambio social (instituciones, formas de interacción, imaginario cultural). Es como si la tecnología se desarrollase en un ámbito externo al medio social. Para Aibar (2001), la idea del determinismo tecnológico ha sido definitivamente descalificada porque el concepto de eficiencia invocado como núcleo de esta lógica no explicaría ciertos cambios tecnológicos y porque, a menudo, no existen criterios muy explícitos de eficiencia. Este autor cuestiona también la supuesta autonomía de la tecnología, de la que habla Winner (1994), aunque reconoce que la tecnología tiene impactos sociales. Para este autor, las relaciones entre tecnología y sociedad son simétricas y mucho más complejas de lo que inicialmente se podía prever (Aibar, 2001).

Las llamadas tecnologías de la información y la comunicación (TIC) son un conjunto de técnicas para gestionar y tratar la información (voz, imágenes y datos) y enviarla de un lugar a otro. Son el resultado de la convergencia de tecnologías como la electrónica, la informática, las redes de telecomunicaciones y otras que han revolucionado la vida y la economía a nivel global. Esta revolución ha sido propiciada por la aparición de la tecnología digital, la cual, unida a ordenadores cada vez más potentes, ha permitido tratar la información como nunca se había hecho, y, por lo tanto, desarrollar el conocimiento.

La llamada sociedad red está basada en la información y el conocimiento a través de las TIC. Antiguamente la información estaba concentrada en textos, monasterios, universidades, etc., mientras que ahora está distribuida en nodos intercomunicados a los que se puede acceder a través de las redes. La información es una materia prima inmaterial que tiene la característica de ser interactiva, incluso en tiempo real, lo cual permite muchas aplicaciones sanitarias. El proceso sanitario, al fin y al cabo, es también un proceso interactivo de información. Las TIC facilitan los intercambios informacionales entre las personas y los profesionales sanitarios. El paciente aporta información sobre su estado a los profesionales, quienes desarrollan procesos de conocimiento sistematizando esa información para diagnosticar y prescribir tratamientos. Últimamente se ha desarrollado en el sector sanitario el concepto e-salud, que se refiere a todo lo 
relacionado con la información digital electrónica en la atención sanitaria, ya sea local o a distancia (Red.es, 2008).

La sociedad red configura la llamada nueva economía y presenta tres características:

a) Es «informacional» al generar y transformar la información en productos.

b) Opera a nivel global y se expande por todo el planeta como forma dominante de organización social de nuestra época.

c) Da lugar a la empresa-red como una organización nueva que funciona como una red con alta flexibilidad y operatividad, de configuración variable, jerárquicamente plana y donde lo importante son las conexiones entre los nodos.

En esta nueva economía cambian radicalmente las formas tradicionales de las relaciones de producción y poder, por lo que se redefinen ámbitos como el mercado laboral, la cultura, la política, el consumo y el Estado.

La sociedad red es una estructura social hecha de redes de información e impulsada por las TIC. Las redes de empresas cobran actualidad bajo el «informacionalismo» porque las nuevas tecnologías realzan la flexibilidad y solucionan los problemas de coordinación y de gobierno. Las redes distribuyen el rendimiento y comparten la toma de decisiones en los nodos según un modelo interactivo. Las redes, por definición, carecen de centro y sólo tienen nodos cuya relevancia radica en las diferentes interconexiones. Cuando los nodos son redundantes, las redes tienden a reconfigurarse: eliminan algunos e incluyen otros nuevos y más productivos. La importancia de los nodos deriva de su capacidad para aportar información valiosa a la red y procesarla de manera eficiente. Las redes operan según una lógica binaria: inclusión/exclusión en función de los valores e intereses dominantes en cada proceso, país u organización social. Sus consecuencias dependen del poder de quienes se benefician de cada una de las múltiples opciones. Una red es como un autómata, una vez que ha sido programada impone su lógica estructural a los humanos, salvo que sea reprogramada, operación que, por lo general, supone un elevado coste social y económico (Castells, 1996).

La hipótesis de este trabajo parte de la idea de que la innovación que supuso la digitalización de imágenes radiológicas y su sinergia con las tecnologías de la información y la comunicación (TIC) promueven la flexibilización de los procesos de conocimiento y posibilitan la subcontratación global del diagnóstico de imagen.

\section{Metodología y resultados}

Estudio exploratorio basado en la opinión de expertos en radiología sobre los cambios tecnológicos y organizativos, los procesos de trabajo y la externalización. Los datos para el estudio se han obtenido a través de entrevistas en profundidad registradas en 
soporte magnético y transcritas textualmente, a partir de las que se ha elaborado un proceso de análisis inductivo. Los sujetos entrevistados han sido varios expertos en el uso y la gestión de tecnologías de imagen de hospitales públicos españoles. También se ha llevado a cabo una revisión bibliográfica sobre la temática del estudio a través de PubMed Central y se han analizado informes relacionados con el cambio organizativo del trabajo radiológico. Por último, se han hecho dos sesiones de observación participante intrusiva en dos unidades de radiología hospitalaria de un hospital público.

La mayoría de las innovaciones médicas proceden de la industria farmacéutica, mientras que la mayoría de las innovaciones diagnósticas y quirúrgicas lo hacen de las aplicaciones de otras ciencias, como la física, la informática, la electrónica, etc. (González López-Valcarcel, 2005a). La competencia entre actores profesionales ha sido una constante en las innovaciones sanitarias. A principios del siglo xx los cardiólogos atendían a los pacientes con angina de pecho administrándoles nitratos. Pero los cirujanos, con una perspectiva diferente, también trataban a estos pacientes mediante intervenciones de alto riesgo y de cuestionable efectividad. En la década de los sesenta los cardiólogos se adelantaron gracias a la innovación farmacéutica de los bloqueadores $\beta$, pero en la década siguiente los cirujanos introdujeron la innovación de los by-pass coronarios, mientras que, en la década de los ochenta, son otra vez los cardiólogos los protagonistas con una técnica mínimamente invasiva: la angioplastia.

En la década de los sesenta, los cirujanos monopolizaban la eliminación quirúrgica de los cálculos renales. Pero en la década de los ochenta aparece la innovación de la litotricia, que se convierte en la terapia de elección y de la que se encargan los gastroenterólogos. En algunos países, como EE. UU, da lugar a la aparición de una nueva especialidad médica basada en la intervención mínimamente invasiva: los radiólogos intervencionistas. Los cirujanos reaccionaron modernizando la cirugía laparoscópica - utilizada hasta entonces por los ginecólogos-, técnica de la que se apropiaron para el tratamiento de los cálculos y otros problemas abdominales. Estas innovaciones —rompedoras_, como las denomina (González López-Valcarcel, 2005b), suponen importantes cambios organizativos y de control profesional sobre las tecnologías innovadoras.

La tecnología, además de un medio para solucionar problemas, ejerce una fuerte fascinación sobre las personas en general, pero especialmente sobre quienes la controlan. Cuando aparecieron en el mercado los equipos de ecografía, los primeros que los usaron y controlaron fueron los radiólogos, pero pronto «todas las especialidades quisieron tener sus ecógrafos y producir sus ecografías» [EOV]. Actualmente, muchas tecnologías, antes exclusivas de la radiología, como ha sido el caso de la ecografía, son usadas por especialidades clínicas como una herramienta más para sus fines diagnósticos. La fascinación de los médicos por la tecnología se evidencia cuando se analizan 
los datos de las asignaciones de nuevas plazas de médicos internos y residentes (MIR) de los años 2003 y 2004, que reflejan que las especialidades médicas con un sofisticado componente tecnológico son las más «cotizadas» (González-López Valcárcel y Barber López, 2005).

\section{Radiología, telerradiología, digitalización y plataformas diagnósticas}

El proceso médico comienza con la valoración de los datos subjetivos y objetivos del paciente para concluir con los llamados juicios clínicos o bipótesis diagnósticas. Para contrastar estos juicios, el propio médico clínico lleva a cabo diferentes pruebas o bien pide otras pruebas a especialistas como los radiólogos para que emitan informes de los hallazgos. Teóricamente, el director del proceso diagnóstico es el médico clínico que estudia al paciente y que recurre a las técnicas de imagen para confirmar o refutar sus juicios y establecer el diagnóstico y tratamiento.

En 1895 Wilhelm Conrad Röntgen descubre las radiaciones ionizantes (rayos $\mathrm{X})$, lo que da lugar al nacimiento de la radiología médica como especialidad médica, también llamada radiodiagnóstico o diagnóstico de imagen. Las radiaciones ionizantes generan imágenes que permiten visualizar partes internas del cuerpo humano. Se desarrolla así una industria productora de tecnología radiológica y de imagen que innova constantemente. De los primeros dispositivos de rayos $\mathrm{X}$ se pasó a otros con mayor calidad de imagen y sencillez de manejo. Se pasó de necesitar ciertos conocimientos para el manejo de los dispositivos a las nuevas generaciones totalmente automatizadas cuyo uso no requiere una gran preparación. De las iniciales imágenes radiográficas estáticas se pasó a técnicas dinámicas como la fluoroscopia, los monitores de TV que intensifican las imágenes en tiempo real o la utilización de contrastes «radiopacos». En la década de los setenta, la sinergia de los rayos $\mathrm{X}$ y la informática da lugar a la innovadora tomografía axial computarizada (TAC), que produce imágenes de cortes axiales muy concretos. Pero existía el problema de los efectos indeseados de las radiaciones ionizantes, lo que fomentó la búsqueda de aplicaciones sin radiaciones. Solucionan este problema los nuevos equipos tecnológicos basados en los campos magnéticos, como la resonancia magnética (RM), los ultrasonidos (ecografía en sus versiones en 3D y 4D), etc. Y se desarrolla la llamada medicina nuclear como un área de la radiología para el diagnóstico y tratamiento tumorales.

Como se puede observar, la evolución de la innovación ha sido constante y cada nueva innovación fascina tanto a radiólogos como a clínicos. Los cambios han afectado incluso a la misma definición de radiología, ya que actualmente bastantes de sus pro- 
ductos no tienen un origen radiológico, sino de otras tecnologías, lo que lleva al nuevo concepto de imagenología.

En los departamentos de radiología existe una división del trabajo entre radiólogos y personal técnico. La evolución de las tareas en los departamentos de radiología la resume un entrevistado:

Hasta los años setenta el radiólogo era como un fotógrafo de interiores, era un técnico de la radiología, tenía el aparato y sabía cuántos miliamperios había que programar. Actualmente de eso se ocupan los técnicos porque el aparato establece automáticamente los parámetros [EAB1].

Producir imágenes radiológicas comenzó siendo una tarea de los radiólogos, pero progresivamente fue siendo transferida al personal técnico. Abandonada la rutina de la producción de imágenes, los radiólogos redefinen su papel centrándose en el análisis de la imagen corporal para diagnosticar posibles patologías. Se centran en lo que definen como "patología compleja» y trasfieren la llamada radiología simple a los médicos clínicos y traumatólogos para que interpreten ellos mismos las imágenes. Se especializan por sistemas corporales (digestivo, torácico, etc.), por tecnologías (TAC, RM, ecografía, etc.) y por edades (infantil, adultos), reproduciendo la estructura de las especialidades médicas. Los radiólogos pasan a ser consultores de los médicos clínicos al desarrollar procesos de conocimiento de la imagen patológica y generar productos intermedios (informe técnico de la imagen) para el diagnóstico final. Asumen la función consultora como resultado del cuestionamiento de su rol porque entregaban las radiografías al clínico tal y como se obtenían y no emitían informes. Sobre esta figura dice un experto:

El radiólogo como consultor que emite informes se inicia con la radiología moderna a finales de los años setenta, con la aparición del TAC, y, más tarde, con la ecografía (EPS).

Al redefinirse, los radiólogos limitaron su campo de acción exclusivamente a la imagen y se alejaron del paciente. Dice un radiólogo entrevistado: «Nosotros perdimos el contacto con el paciente, sólo necesitamos imágenes». Consideran su valoración más holística que la de los clínicos: «Los radiólogos tenemos una visión global, mientras que los clínicos tienen una visión más particular» (EPS).

En su redefinición profesional, los radiólogos abrieron recientemente un nuevo campo a través de las especialidades intervencionistas. Estas áreas de conocimiento integran diagnóstico y terapia mediante una intervención mínimamente invasiva por procedimientos de cateterización guiados por imagen en tiempo real. Supone generar 
un producto autónomo y finalista y no intermedio como es el diagnóstico de imagen, pero que entra en conflicto con otros actores. Uno de los conflictos se produce dentro del propio grupo de radiólogos entre los que se centran sólo en imágenes y los que asumen la terapéutica intervencionista (Martínez-Rodrigo y Martí-Bonmatí, 2008). El otro conflicto se produce con las especialidades quirúrgicas, como las vasculares, que compiten por tratar el mismo tipo de diagnóstico y de pacientes pero utilizando vías diferentes. Los radiólogos que monopolizan la tecnología diagnóstica aplican la terapia directamente a los pacientes a los que diagnostican, lo que resta pacientes a los cirujanos vasculares. Los médicos vasculares, que antes pedían imágenes radiológicas, observan cómo los radiólogos intervencionistas se apropian de «sus» pacientes. Para impedirlo, reclaman sus propios recursos tecnológicos para integrar, también ellos, el proceso diagnóstico-cirugía y evitar a los consultores-intervencionistas de la radiología.

En los últimos años dos innovaciones tecnológicas han transformado radicalmente el escenario de la radiología médica. Son la digitalización de imágenes y las nuevas tecnologías de la información y la comunicación (TIC). La digitalización de imágenes radiológicas, surgida a mediados de los años ochenta, revolucionó el tratamiento de las imágenes al permitir editarlas, ampliarlas, redimensionarlas, focalizar partes de ellas, etc. Las imágenes se convierten en bits de información que pueden enviarse como paquetes a través de las redes de transmisión de datos de alta capacidad a lugares de todo el mundo donde expertos las pueden interpretar. Es el nacimiento de la telerradiología, que consiste en el envío de imágenes y la recepción de los informes de evaluación de éstas. Este procedimiento se articula con el llamado paradigma e-salud, basado en la aplicación de las TIC a la atención sanitaria, al diagnóstico, a la gestión de la información y al tratamiento de la enfermedad, también conocido como telemedicina (Eysenbach, 2001).

La producción de imágenes necesita un centro (hospital, centro de salud, empresa, unidad móvil, etc.), una tecnología adecuada y la proximidad del demandante. En cambio, los procesos de conocimiento para interpretar la imagen prescinden del paciente (despersonalización), y del espacio y del tiempo en que se producen. Si los radiólogos ya no producen las imágenes porque lo hace el personal técnico, ni tampoco necesitan la presencia de los pacientes porque sólo quieren imágenes, parece factible que su interpretación pueda hacerse desde cualquier lugar. Cuando en España es medianoche y un hospital necesita una segunda opinión o interpretar un TAC, a esa hora en Buenos Aires es de día y están operativos consultores de empresas de telerradiología a las que se puede subcontratar el servicio. Este hecho lo explica bien el caso de la clínica virtual sueca Telemedicine Clinic — que trabaja para más de 100 centros sanitarios nórdicos y de otros países-, que se instaló en Barcelona porque no necesitaba estar en Estocolmo para prestar sus servicios. Se plantea así que los servicios de interpretación de imáge- 
nes se puedan subcontratar o externalizar (outsourcing) a otras empresas o ámbitos. La externalización supone traspasar actividades que antes realizaban los radiólogos en el propio hospital a otras organizaciones, sean públicas o privadas, generalmente para reducir los costes y flexibilizar los recursos humanos. En EE. UU., la corriente de subcontratación de estos servicios se centra en la India debido a las ventajas de tener un mismo idioma, los bajos costes y el cambio horario con respecto a EE. UU. (Nishigandha Burute y Bhavin Jankharia, 2009).

La externalización, desde la perspectiva de una organización pública, no equivale necesariamente a privatización cuando se traspasa a otra empresa pública, pero se halla en los límites. Cuando una organización necesita bienes o servicios, puede obtenerlos con sus propios medios o contratarlos externamente. Es el llamado dilema de make or buy. Las ventajas potenciales de externalizar son: a) facilitar la gerencia organizativa al centrarse en los procesos nucleares; b) flexibilizar y reducir la rigidez productiva al trasladar costes fijos a variables, y c) reducir los costes, porque, supuestamente, la organización a la que se externaliza obtiene economías de escala (Repullo, 2008).

Cuadro 1. Ventajas y limitaciones de la externalización del diagnóstico de la imagen

\begin{tabular}{|l|l|}
\hline Ventajas & Limitaciones \\
\hline Ventajosa relación coste-beneficio. & \\
Servicio las 24 horas los 365 días del año. & Cuestiones legales (confidencialidad). \\
Acceso de pequeños centros a alta especialización. & Infraestructuras tecnológicas. \\
Solución a la escasez de profesionales. & Interacción con el paciente. \\
Reducción de recursos humanos hospitalarios. & Relación entre clínicos y especialistas. \\
Prescindir de la presencia física de radiólogos. & \\
Alta especialización por casuística. & \\
\hline
\end{tabular}

Algunas de las modalidades de externalización de la interpretación diagnóstica de la imagen más habituales son:

+ Externalización a nuevas organizaciones nacionales con plataformas que centralizan on line las imágenes digitalizadas enviadas desde los centros sanitarios. Un ejemplo sería el caso de la Unidad Central de Radiodiagnóstico (UCR) o «anillo radiológico», empresa pública de la Comunidad de Madrid. Es una organización que está operativa las 24 horas los 365 días del año. Está constituida por un grupo de radiólogos consultores altamente especializados porque manejan una abundante casuística y se dedican a analizar imágenes y emitir informes diagnósticos. Los profesionales disponen de una plataforma tecnológica que asocia imagen e informe y los médicos clínicos acceden on line a los resultados. 
- Externalización mediante privatización de la producción y la interpretación de las imágenes diagnósticas. Los servicios de salud de algunas comunidades autónomas tienen contratos de externalización de servicios de alta tecnología diagnóstica como resonancias magnéticas, TAC, ecografías, etc. Existe una emergente oferta privada de servicios de consultoría de imagen, como eDiagnostic, RT2S (Real Time Telemedicine Services, S. A.), Drim, etc.

- Externalización internacional global, también denominada outsourcing internacional, offshoring o deslocalización. Supone transferir desde países desarrollados imágenes para que expertos remotos diagnostiquen o emitan una segunda opinión. Generalmente la oferta de estos servicios está situada en países en desarrollo que aprovechan las diferencias salariales entre los profesionales de diferentes países y que ofrecen un servicio de calidad a bajo coste. The New York Times publicó en el 2003 un artículo titulado «Who's reading your xray?» ${ }^{2}$ en el que se hablaba de la corriente de subcontratación radiológica desde centros médicos de EE. UU. hacia centros de la India donde se diagnosticaban las imágenes. Varios estudios tratan de la experiencia de externalización internacional del diagnóstico en la India (Arjun, et alii, 2004) de TAC realizados en EE. UU., así como de la relativa seguridad técnica de la telerradiología y la rapidez de respuesta de estos servicios (Wachter, 2006).

La primera oleada de externalización internacional afectó a actividades de trabajo poco cualificado (producción de bienes, mantenimiento de sistemas de información y atención al cliente), pero ahora estamos en la «segunda oleada», que afecta a los procesos de conocimiento de servicios de diagnóstico de imagen. Las organizaciones están comenzando a buscar talento en países emergentes para reducir los costes. La resistencia a externalizar responde a las diferencias culturales con el país receptor, a las dificultades con el idioma, a la resistencia corporativa y a la incertidumbre sobre la aceptación del cliente (Ricart y Agnese, 2006).

Para implantar este modelo emergente se están desarrollando plataformas vinculadas a servidores locales, regionales o globales con bancos de imágenes y con otras herramientas aplicadas para interpretar y emitir informes a distancia. Los bancos de datos almacenan las imágenes enviadas, de modo que cualquier radiólogo perteneciente al sistema, se halle donde se halle, puede acceder de modo remoto utilizando las herramientas del propio sistema. Así, el radiólogo puede acceder a la plataforma desde cualquier lugar con conexión a la red mediante su laptop personal o estación de trabajo. Esta forma organizativa supone la creación de redes de especialistas vinculados a uno o más centros que operan a diferentes niveles para atender las demandas de interpreta-

2 The New York Times (2003). «Who's Reading Your X-Ray?» Disponible en: http://www.nytimes.com/2003/11/16/ business/who-s-reading-your-X-ray.html?pagewanted $=1$ 
ción de imágenes. Es una nueva organización flexible y descentralizada que permite a cada actor profesional asociado a la red aportar su conocimiento casi como un freelance. Para el responsable de la empresa española e-Diagnostic, su objetivo es tener a «cientos de médicos a variable». Drim, otra empresa del grupo, con 22 médicos en el territorio español, se compromete a entregar el informe diagnóstico en un tiempo máximo de 30 minutos (García, 2010). Paralelamente a la descentralización, se produce un control centralizado del sistema o la plataforma de gestión de las imágenes y aplicaciones que algún actor «invisible» controla.

Este tipo de organización tiene la ventaja de facilitar el acceso a conocimiento especializado a pacientes de comunidades u hospitales pequeños que carecen de especialistas permanentes y a los que de otra manera no tendrían acceso. También permite, por ejemplo, obtener rápidamente segundas opiniones diagnósticas o sustituir a radiólogos poco especializados por otros altamente expertos (Wachter, 2006).

José Repullo, experto en el tema, cuando escribe en su blog sobre la crisis de los servicios centrales hospitalarios, como la radiología o los laboratorios, dice:

los servicios centrales pasan a considerarse como un suministro de servicios que se separa del núcleo clínico de producción, y que, por lo tanto, se aparta de la cadena de valor' propia del sector (entrando en la categoría de servicios hosteleros y generales).

La reestructuración profesional que supone la externalización radiológica destruye el monopolio profesional de los radiólogos hospitalarios, tal y como lo expresa la presidenta de la Sección de Gestión y Calidad de la Sociedad Española de Radiología Médica (SERAM):

Hace unos años ejercíamos el monopolio, ahora ya no. Mientras, la externalización crece imparable.

Varios radiólogos entrevistados consideran que la externalización descentralizada o la concentración de la consultoría radiológica en organizaciones externas será un hecho inevitable. El llamado anillo radiológico (UCR) implantado en Madrid previsiblemente «se vaya a extender al resto de España». Creen que la externalización local o regional será el primer paso, pero «tarde o temprano va a haber externalización a nivel mundial». Actualmente las barreras para la implantación de este sistema son «el manejo de las TIC y el idioma». Consideran que es una «reorganización operativa que supone una fuerte flexibilización laboral» (EOV). Consideran el término externalización como un eufemismo de privatización y la atribuyen a la búsqueda de la eficiencia,

3 Blog de José Repullo. http://buengobiernosns.blogspot.com/2007/12/la-externalizacin-como-disgregacin.html 
a la escasez de recursos humanos por la reducción de las guardias de presencia física a radiólogos mayores de 55 años en los hospitales públicos, a la reordenación de recursos humanos entre centros y a la escasez de recursos económicos.

Los radiólogos entrevistados reconocen un determinismo tecnológico «sobre sus roles profesionales» y también la inevitable necesidad de adaptarse a los cambios (EPS). Aceptan las innovaciones como una consecuencia inevitable, pero también expresan incertidumbres sobre el futuro de su especialidad cuando matizan que «no es lo ideal»+ «Telerradiología sí, pero bien entendida y realizada». Un profesional considera la telerradiología como una «herramienta de gestión que tienen que liderar los propios radiólogos».

Algunos tienen la sensación de que cada vez son menos importantes en los hospitales y exigen mantener su actual presencia física porque «la ausencia física del radiólogo le desvincula considerablemente del proceso de toma de decisiones» (Rodríguez Carenas, 2009b). Buscan asideros que mantengan su situación; en este sentido, un entrevistado afirmaba: «Las ecografías son radiólogo-dependientes» (EPS).

Las principales reticencias se centran en cuestiones de tipo legal: «la ubicuidad de la imagen», «la globalización de la interpretación radiológica y el aparente anonimato», la vulneración de la confidencialidad de los datos no protegidos, la posibilidad de que existan evaluadores ilegales (intrusismo), etc. (Rodríguez Carenas, 2009b). Un profesional sugiere regular la externalización global mediante un contrato con altas estipulaciones de seguridad que deberían ser autorizadas previamente por el director de la Agencia Española de Protección de Datos. Si existe un error de diagnóstico, plantean: ¿a quién presentar la reclamación? ¿Quién es el responsable?

Sobre los nuevos profesionales que se incorporan a la especialidad como médicos internos residentes (MIR), dice un entrevistado:

Los radiólogos jóvenes tienen fascinación tecnológica, quieren hacer TAC, pero no son conscientes de que posiblemente en el futuro serán informados en Bangladesh. Se desentienden de las ecografías y otras técnicas básicas, y piden que se deriven a la atención primaria, sin darse cuenta de que atacan sus posibilidades de desarrollo profesional de futuro (ESS).

La radiología como especialidad médica ha estado sometida a una constante transformación derivada de los cambios tecnológicos y la necesidad de redefinir su papel. Primero, los radiólogos fueron técnicos «fotográficos» que eran conocedores expertos de los aparatos productores de imágenes. Más tarde, asumen el rol de consultores de apoyo al diagnóstico clínico. Con las TIC se convierten en imagenólogos virtuales. Y, últimamente, se autonomizan del médico clínico e integran diagnóstico y terapia míni- 
mamente invasiva con el soporte de la imagen; es la llamada radiología intervencionista endovascular, neurorradiológica, etc. Incluso surgen nuevos campos de intervención, como la oncología radioterapéutica. Por lo tanto, el escenario sigue abierto a la redefinición.

\section{Conclusiones}

La tecnología es la aplicación de la racionalidad científica y burocrática para la resolución de problemas y la eficiencia. Son los valores dominantes de la sociedad occidental (Weber y Habermas). La tecnología es pura acción racional. La externalización que hemos tratado es el fruto de una racionalización organizativa y de los procesos.

Para los constructivistas y los partidarios de la teoría del actor-red, la innovación tecnológica es una consecuencia de la competencia y el conflicto entre actores (incluida la industria) para poder imponer su definición de cómo resolver problemas o controlar la tecnología. Mientras los radiólogos hospitalarios ofertaron productos tecnológicos intermedios de apoyo al médico clínico, no hubo conflictos, pero el conflicto surgió cuando algunos usaron tecnologías de imagen para integrar diagnóstico y tratamiento (imagen y terapia).

Varios factores del entorno social contribuyen al cambio en los procesos de la imagen médica.

1. La crisis económica en curso, las dificultades financieras de los sistemas sanitarios y los valores del paradigma de la nueva gestión pública, paradigma cuya agenda política busca la eficiencia y reducción de costes, el adelgazamiento organizativo y la flexibilidad de los recursos humanos. La innovación tecnológica, la subcontratación y la externalización de los servicios son respuestas a estas demandas. Por otro lado, la industria innova constantemente tecnologías cada vez más sofisticadas orientadas a la búsqueda de la calidad y la eficiencia, es decir, a producir más calidad con menos costes.

2. Para Lowenstein (2002), la telerradiología ha sido potenciada por la escasez de profesionales y no por la tecnología en sí. La descentralización de los departamentos de imagen de hospitales y su concentración en organizaciones especializadas en diagnóstico de imagen es una fórmula organizativa eficiente que hace frente a la escasez de radiólogos, incrementa la especialización profesional y aprovecha los rendimientos de escala, de manera que con menos recursos humanos se puede ofrecer más. Esta fórmula organizativa va a suponer un primer paso hacia una externalización más amplia.

3. Con el desarrollo de las TIC y la digitalización de imágenes aparecieron nuevas organizaciones nacionales e internacionales descentralizadas de los hospitales que 
ofrecen servicios de diagnóstico de imagen remoto. Son organizaciones flexibles características de la sociedad red que operan en mercados globales gracias a las redes de comunicaciones. Estas organizaciones desbordan las regulaciones corporativas y proteccionistas de las profesiones liberales. Cuando los radiólogos se alejan progresivamente de los pacientes, convierten el diagnóstico de imagen en una cuestión puramente técnica que trasciende los límites de la particularidad temporal, el espacio físico y la cultura. Esta decisión de los radiólogos, como actores microsociales, contribuye a un cambio sutil que termina afectando a su propio rol profesional, pero los «hechos sociales» de lo macrosocial (la industria y los valores de eficiencia) terminan imponiéndose sobre las decisiones de los actores micro. Son las «consecuencias no buscadas de la acción» que relacionan lo micro con lo macro. Los cambios tecnológicos reconfiguran los procesos organizativos y laborales. Aquí es pertinente la idea de Winner de que la tecnología cambia la forma de vida y se autonomiza de lo humano. También podemos estar de acuerdo con la idea de Postman de que ya nada volverá a ser como antes en el escenario de la radiología médica porque es improbable la reversibilidad del proceso tecnológico debido a su eficiencia técnica.

4. Primero se simplificó la producción de la imagen, después el paciente se independizó de su imagen corporal, más tarde se externalizaron los procesos de conocimiento para el diagnóstico y probablemente en el futuro asistamos a una nueva racionalidad basada en el desarrollo de sistemas expertos automatizados de interpretación diagnóstica de imágenes. La acumulación de casuística en bancos de imágenes permitirá diseñar aplicaciones simplificadoras de la interpretación con herramientas de alerta y control ante desviaciones patológicas. Es el resultado de la formalización de procesos y su incorporación al software (Mintzberg, 1991), porque cuanto mayor es la formalización de los procesos mayores son las probabilidades de automatizar el diagnóstico y su desempeño por operarios de baja cualificación. La automatización va más allá: no solamente regula y controla el trabajo humano, sino que lo sustituye ventajosamente. La sistematización del conocimiento del trabajo obrero, emprendida por los ingenieros de Taylor, condujo a la automatización del trabajo en las cadenas de montaje y más tarde a la robotización. Los procesadores de texto descalificaron el trabajo de las secretarias. ¿Por qué no puede ocurrir lo mismo con la evaluación de las imágenes médicas? Esta misma lógica ha llevado al Ministerio de Fomento a anunciar recientemente el estudio de la sustitución de parte de los controladores aéreos por un innovador sistema de información para la navegación aérea.

Todo lo anterior configura un escenario de organizaciones características de la sociedad red, que desarrollan procesos de conocimiento con las imágenes corporales y la información disponible sobre patologías. Los actores de los procesos están interconectados flexiblemente a redes a las que contribuyen de manera variable y no jerarquizada. 
Unos, los expertos más experimentados y especializados que aporten valor añadido y calidad a la red, serán potenciados y disfrutarán de prestigio y poder profesional, mientras que los que no aporten valor a la red serán excluidos. El debilitamiento del poder profesional de algunos actores contribuye a las dudas e incertidumbres sobre el futuro profesional de una especialidad marcada por los cambios tecnológicos y sociales.

Las nuevas tecnologías modificaron el escenario organizativo de la imagenología médica al crear organizaciones en red, flexibles y globales cuya actividad dependerá de la demanda global. En este escenario, los radiólogos, como actores relevantes en los procesos de conocimiento, perderán el control sobre algunas de «sus» tecnologías en beneficio de otros actores clínicos que aspiran a controlar sus medios tecnológicos para integrar diagnóstico y tratamiento.

McKinlay y Marceau (2002) destacan que la globalización, la revolución informativa y de comunicaciones, y la competencia de otros trabajadores de la salud en ámbitos que tradicionalmente monopolizaban los médicos son factores extrínsecos, ajenos al control profesional, que suponen el declive de la edad de oro de estos últimos.

\section{Bibliografía}

Aibar, E. (2001). Fatalismo y tecnología: ¿es autónomo el desarrollo tecnológico? Accesible en: http://www.uoc.edu/web/esp/art/uoc/0107026/aibar.html

Arjun, K.; Neklesa V. P; Pham D. T. et alii (2004). Implementation of an International Teleradiology Staffing Model. Radiology, 232 (2)ः 415-9.

Burute, N. y Jankharia, B. (2009). «Teleradiology: The Indian perspective». Indian Journal of Radiology and Imaging, 19 (1): 16-18

Callon, M. (1995). «Technological conception and adoption network: Lessons for the CTA practiotioner», en A. Rip; T.J. Misa y J. Sснот, (eds.). Managing Technology in Society. Londres: Pinter, 307-330.

Castells, M. (1996). La Era de la Información. Vol. 1. La sociedad red. Madrid: Alianza editorial.

Eysenbach, G. (2001). «What is e-health?». Journal of Medical Internet Research, 3 (2): e20.

Fleuren, M.; Wiefferink, K. y Paulussen, T. (2004). «Determinations of innovatión within health care organizations: Literature review and Delphi study»+ Int J Qual Health Care, 16 (2): 107-123.

García, B. (2010). «Su hospital puede estar en la red. La clínica eDiagnostic busca dominar en España el negocio de la telemedicina». El País Negocios, Domingo $24 / 1 / 2010$. 
González-López Valcárcel, B (2005a). «Cambio tecnológico en sanidad. Determinantes, efectos y políticas», en B. González López-Valcárcel. Difusión de nuevas tecnologías sanitarias y políticas públicas. Barcelona: Masson.

González-López Valcárcel, B (2005b). Difusión de nuevas tecnologías sanitarias y políticas publicas. Barcelona: Masson.

González-López Valcarcel, B.; Barber López, P. (2005). «Programas MIR como innovación y como mecanismo de asignación de recursos humanos», en $\mathrm{R}$. Meneu; V. Ortún Rubio y F. Rodríguez-Artalejo (eds.). Innovaciones en gestión clínica y sanitaria.

Habermas, J. (1984). Ciencia y técnica como ideología. Madrid: Tecnos.

Hughes, T. (1996). «Impulso Tecnológico», en M. Smith y L. Marx (eds.). Historia y Determinismo Tecnológico. Madrid: Alianza.

Latour, B. (1992). Ciencia en acción. Barcelona: Labor.

Lewis, M. (2000). Técnica y civilización. Madrid: Alianza.

Lowenstein, G. (2002). «New realities shape future radiology delivery models», Radiology Management, 24 (2): 22-5.

Martínez-Rodrigo, J.J.y Martí-Bonmatí, L. (2008)+ «Competencias profesionales: del conflicto a la oportunidad». Radiología, 50 (1):5-10

McKinlay, J.B.y Marceau, L.D. (2002), «The end of the golden age of doctoring». International Journal Health Service, 32 (2): 379-416

Mintzberg, H. (1984). La estructuración de las organizaciones. Barcelona: Ariel.

Peiró, S. y Bernal-Delgado, E. (2006). «¿A qué incentivos responde la utilización hospitalaria en el Sistema Nacional de Salud?». Gaceta Sanitaria, 20 (1): 110-6.

Pinch, T. y Bijker, W. E. (1987). "The Social Construction of Facts and Artifacts: Or How the Sociology of Science and Socioloy of the Technology Might Benefit Each Other», en The Social Construction of Technological Systems: New Directions in the Sociology and History of Technology. Cambrige (MA): MIT Press.

Postman, N. (1994). Tecnópolis: la rendición de la cultura a la tecnología. Barcelona: Galaxia Gutenberg/Círculo de Lectores.

Red.es (2008), Las TIC en el Sistema Nacional de Salud. El Programa Sanidad en Linea. Madrid: Red.es. Accesible en: http://www.ontsi.red.es/sanidad/articles/id/3032/ las-tic-el-sistema-nacional-salud.html [Consulta el 7/3/2010]

Repullo, J.R. (2008). «Externalización, eficiencia y calidad (Primera parte). Público y privado en la sanidad». Revista Calidad Asistencial, 23 (2): 83-7

Ricart, J.E. y Agnese, P. (2006). El offshoring en España: Causas y consecuencias de la deslocalización de servicios. Navarra: IESE.

Rodríguez Carenas, D. (2009a). «Telerradiología, una solución a la falta de profesionales ¿puntual o de futuro?». Diario Médico, 4/7/2009. Accesible en: http:// 
www.diariomedico.com/2009/04/07/area-profesional/gestion/telerradiologiasolucion-falta-profesionales-puntual-futuro

Rodríguez Carenas, D. (2009b). «Los peligros legales de la externalización de la radiología». Diario Médico, 13/4/2009. Accesible en: http://www.diariomedico. com/2009/04/07/area-profesional/gestion/peligros-legales-externalizacion-radiologia.

WACHTER, R. (2006). International teleradiology, 354 (7):662-663.

Wachter, R. (2006). «The 'Dis-location' of U.S. Medicine-The Implications of Medical Outsourcing». The New England Journal of Medicine, 7 (354): 661-665.

Weber, M. (2003). La ética protestante y el espiritu del capitalismo. México: FCE.

WinNer, L. (1987). La Ballena y el reactor: una búsqueda de los límites en la era de la alta tecnología. Barcelona: Gedisa.

Winner, L. (1979). Tecnología autónoma: La técnica incontrolada como objeto del pensamiento político. Barcelona: Gustavo Pili. 